\title{
Comparative Assessment of Two Thermodynamic Cycles of an aero-derivative Marine Gas Turbine
}

\author{
M. U. Bonet ${ }^{1}$, P. Pilidis ${ }^{2}$ \\ 1. Department of Mechanical Engineering, Nigerian Defence Academy, P.M.B. 2109, Kaduna, Nigeria \\ 2. Buiding 52, School of Engineering, Cranfield University, MK43 OAL, Bedfordshire, United Kingdom
}

\begin{abstract}
This paper explores the gas turbine potentials that are fully enhanced by the use of intercooling and thermal recuperation as an engineering option available in the design of gas turbines and offered for marine applications. It examines the off-design performance of two different cycle designs of a $25 \mathrm{MW}$ aero-derivative engine by modelling and simulating each of them to operate under conditions other than those of their design point. The simple cycle model consists of a single-spool dual shaft layout while the advanced model is represented by an intercooled-recuperated cycle that runs on a dual-spool and is driven through a three shaft configuration. In each case, the output shaft is coupled to a power turbine through which the propulsion power may be transmitted to the propeller of the vessel to operate in a virtual marine environment. An off-design performance simulation of both engines has been conducted in order to investigate and compare the effect of ambient temperature variation during their part-load operation and particularly when subjected to a variety of marine operating conditions. The study assesses the techno-economic impact of the complex design of the advanced cycle over its simple cycle counterpart and demonstrates its potential for improved operating cost through reduced fuel consumption as a significant step in the current drive for establishing the marine gas turbine engine as a viable alternative to traditional prime movers in the ship propulsion industry.
\end{abstract}

\section{Introduction}

Producing great amounts of energy for its size and weight, the gas turbine has found increasing service in more than 40 years and in conjunction with growth in materials technology and increase in compressor pressure ratio, thermal efficiency has increased from $15 \%$ to $45 \%$. It is a continuous flow non-reciprocating internal combustion engine whose initial concept was meant for aircraft propulsion so as to overcome the drawbacks of its reciprocating piston counterpart in the aerospace industry. When modified and adapted for land-based and off-shore applications, it becomes an aero-derivative gas turbine whose lightweight attracts it particularly to naval ship propulsion applications where weight and space are of primary importance [1] and over the last 40 years, Rolls-Royce (RR) and General Electric (GE), which are some of the world's topmost original equipment manufacturers (OEMs) of gas turbines have since introduced a good number of them into the marine market, starting with the RR's commercially successful version of the 3MW industrial Proteus engine followed by the Tyne (4MW), the Spey (12.5, 18 or 19MW) [2] and the Olympus models [3] which are all configured on the basis of the simple thermodynamic cycle. The implementation of the simple cycle technology by GE has shown tremendous success in its LM2500 series [4] [5] whose output power transmission is achieved through a power turbine and an output shaft unto which the desired load may be coupled. Another engineering option for advancing the performance of the gas turbine is that of the dual-spool, three-shaft MT30 Marine Trent MT30 [6] complex layout, composed of low and high pressure spools aerodynamically coupled to the free power turbine for the purpose of boosting the basic simple cycle thermal efficiency.

In order to overcome the part-load performance challenges when used as a ship propulsion prime mover, the gas turbine can be installed and configured to operate in combination with other traditional ship propulsion prime movers such as the diesel engine either as 'Combined Diesel and Gas turbine' (CODAG) or as 'combined diesel or gas turbine' (CODOG) configuration. A big and small gas turbine may also be coupled together in a father and son relationship to either operate in a 'combined gas turbine and gas turbine' (COGAG) or 'combined gas turbine or gas turbine' (COGOG) in which boost power for top speed operations is to be provided by the bigger engine [8] while low speed fuel economy at low power settings is to be provided by the smaller one whenever necessary. Another combination 'combined diesel Electric and Gas turbine (CODLAG)' is also used in practice as an option that has been developed and adopted for the propulsion of high speed naval vessels in which a controllable pitch propeller is usually fitted so as to match the different operating conditions for each of the prime movers [9].

A general layout of both thermodynamic cycles is illustrated in Figure 1 showing the flow of the working fluid and how the desired output power is derived via a free power turbine. In practice, Rolls-Royce intercooled recuperated marine model WR21 [7] [8] whose SFC curve illustrated in Figure 2 is showing significant fuel saving capability when compared with other existing cycle options. Its cycle layout incorporates 
intercooling and heat exchange for the purpose of improving part-load performance at low power demand operations. The intercooler, which represents an air-to-liquid heat exchanger, is useful during the compression process to enhance the specific power of the engine by cooling the airflow midway through the compression process [10].
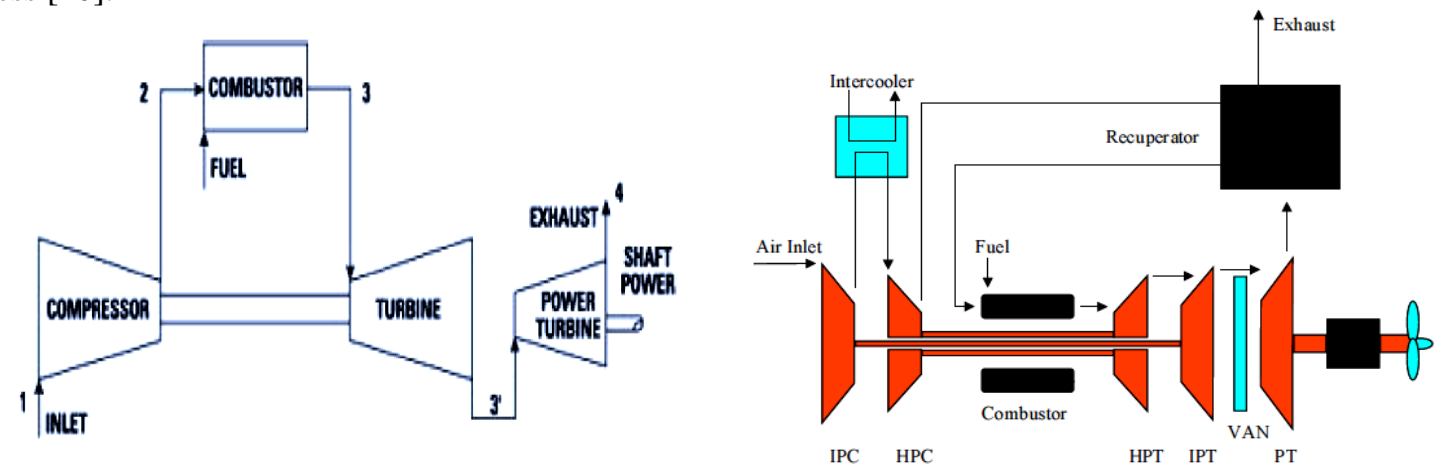

Figure 1: The component layout and thermodynamic cycle configuration of the simple cycle [1] and the ICR model of the gas turbine [7]

The added complexity results in a reduction of the energy required during compression which enhances a higher power output. The recuperator on the other hand transfers the waste heat from the exhaust gases to the engine airflow in order to reduce the fuel required during combustion thereby achieving better performance. Furthermore, the incorporation of an intercooler between the compression stages of the low and high pressure spools increases the specific power of the engine while the amount of work needed to drive the compressor is reduced and this increases the net power available.

This advanced cycle is capable of achieving between $40 \%$ to $46 \%$ thermal efficiency which is considerably higher than the about $36 \%$ to $37 \%$ achievable in the simple cycle. This is only slightly less than the about $50 \%$ achieved by a combined cycle where a steam turbine is installed to use steam from boilers fired by waste heat from the gas turbine to generate additional power. With an estimated lifetime of up to $100,000 \mathrm{hrs}$ the ICR heat exchanger may be of a compact plate and fin design [11] and in contrast to the combined cycle, it is inherently simpler, smaller and cheaper and does not require hours to warm up. It also has considerable waste heat left in the exhaust for possible onboard utilization along with a facility to generate more when the recuperator and intercooler are bypassed. Considered as the most advanced marine gas turbine currently available, it exemplifies the next generation of ship propulsion prime movers aimed at offering a combination of high power density, low fuel consumption and environmentally friendly solutions in the maritime industry.

Another aero-derivative gas turbine with a regenerator is the General Electric LM2500R which also employs a recuperator (exhaust gas-to-compressed air heat exchanger) to recover high grade heat in the gas turbine exhaust by means of a counter-current flow compressor discharge air that, after heating, flows on to the combustor. In Figure 2, the specific fuel consumption (SFC) of some practical cycles are drawn to illustrate the successful design investments that have been made and are aimed at the improvement of gas turbine engine performance in which the ICR reveals the best results.

\section{Engine Performance Simulation Platform}

The performance of any gas turbine can best be defined as the end product that any manufacturer can sell to its customers and the thread that sews all other gas turbine technologies together. It may be summarised as the thrust or shaft power that may be delivered for a given fuel flow, life, weight, emissions, engine diameter and cost which must be achieved while ensuring a stable and safe operation throughout the operating envelope under all steady and transient conditions. This investigation however limits itself to the running cost that relates to the consumption of fuel in the course of operating the selected models under state conditions.

'Turbomatch'[12] which is a product of ongoing research efforts in industrial and aircraft gas turbines at the power and propulsion Department of Cranfield University in the UK [13], has the capability of carrying out design point and off design calculations. At its design point mode, it provides engine performance and size data as illustrated in Table 1, while at off-design it predicts the engine performance for varying engine throttle setting (rotational speed, combustor exit temperature, or fuel flow). Its working principle is based on a thermodynamic mass and energy balance from which the off design calculations may be conducted through an iterative generic method in conjunction with experimentally derived maps that are scaled to match the design point of the simulated engine. The choice of using the embedded maps is a result of the structure of the simulation program which comprises several pre-programmed modules that correspond to models of the 
individual components, such as compressors, burners, turbines, mixers, nozzles, heat exchangers, splitters and the power turbines. Its modular structure enables the detailed design and simulation of any modern industrial or aero gas turbine engine. The simulation software has been validated against commercially sensitive data and further details can be found in [14], [15] and [16], while the working design point and off-design calculations are fully described in [12].

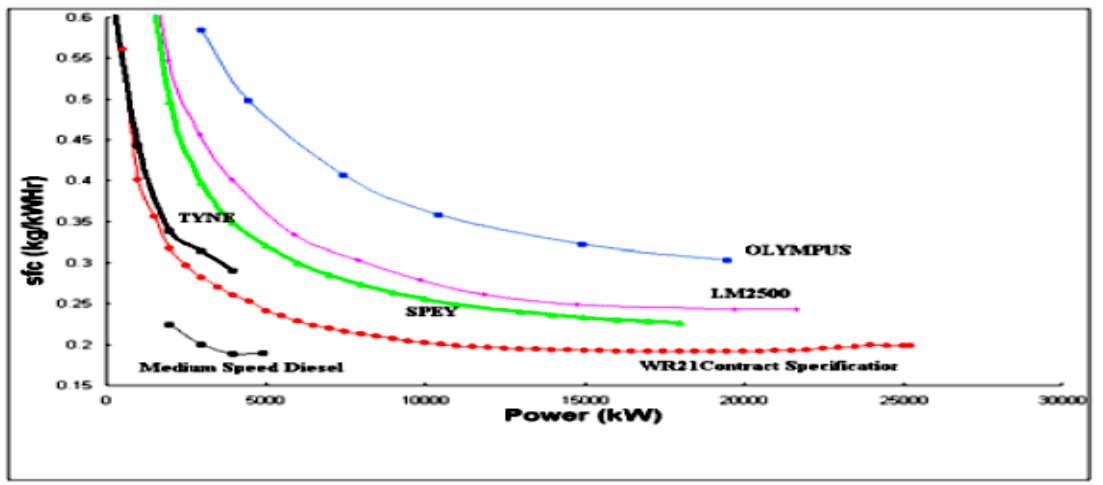

Figure 2: The specific fuel consumption (SFC) profiles of some existing Marine gas turbine engines [13].

Effectively, values of compressor pressure ratios, turbine entry temperatures and component efficiencies as well as pressure losses (regarded as the basic design parameters of any gas turbine) were specified as the main design point input variables. The procedure proceeded with the determination of the free stream static and total conditions at a given altitude using the International Standard Atmosphere (ISA) in order to enable the evaluation of the conditions at exit from the intake. Implementing the 'TURBOMATCH' program enabled the modelling and simulation of the selected gas turbine engines with the input data fashioned in manner that allows the building of an engine structure and the component parameters resulting in a compressor characteristic map. While taking many other important factors such as the expected component efficiencies, air bleeds variable fluid properties and pressure losses into account, detailed thermodynamic calculations over a wide range of pressure ratio and turbine entry temperature limits were conducted. The simple and advanced cycle models were then simulated at design and steady state off-design conditions by monitoring and recording every engine parameter and the output data was obtained in a spread sheet for further analysis. Predictable part-load performance in applications where considerable running at low power settings is of major importance and its effect on the specific fuel consumption (SFC) as well as the effect of high and low ambient temperatures and pressures on its maximum output are of high importance to the customer and as such, manufacturers must be prepared to guarantee the performance available at any specified condition hence the propulsion plant of any marine vessel has to be designed to allow for flexibility in operation over a wide range of power levels while still maintaining operating efficiency without incurring losses in fuel economy.

The drawing up of a data file that consists of all necessary input and output parameters of the component parts when assumed to have been coupled together according to the cycle configuration of the model under investigation. The simulated off-design performance results have been interpreted and analysed through establishing component characteristics to enable the location of relevant corresponding operating points when the engine is running at a steady speed or in equilibrium for a series of non-dimensional speeds in the form of an equilibrium running diagram. A comparative performance analysis of the two engines was conducted and the result is demonstrated in the form of compressor characteristic maps for each of them as illustrated in Figure 4 for the simple cycle model and in Figure 3: for the advanced cycle model respectively. It will be observed that the ICR consists of a low pressure spool as well as that of a high pressure in order to facilitate the incorporation of the heat exchangers necessary for the cycle layout for it.

\section{Comparative Performance Results}

Compressor performance has been evaluated and represented by plotting constant aerodynamic speed lines as a function of delivery pressure and corrected mass flow. The actual mass flow and speeds are corrected by a factor of $\frac{\sqrt{T_{1}}}{P_{1}}$ and $\frac{1}{\sqrt{T_{1}}}$ respectively through a non-dimensional method so as to reflect variations in inlet pressure and temperature. This leads to the compressor performance being expressed through a variation of the delivery pressure $\mathrm{P}_{2}$, and temperature $\mathrm{T}_{2}$, the mass flow $\mathrm{m}$, rotational speed $\mathrm{N}$, and the corresponding inlet conditions in the form of the following non-dimensional groups: 


$$
f\left(\frac{P_{2}}{P_{1}}, \frac{T_{2}}{T_{1}}, \frac{m \sqrt{T_{1}}}{P_{1}}, \frac{N}{\sqrt{T_{1}}}\right)=0 \text {; where the suffixes } 1 \text { and } 2 \text { represent the compressor inlet and outlet pressures }
$$

and temperatures respectively, while the $m$ and the $N$ represent the mass flow and rotational speed respectively.

Table 1: Design point parameters of the investigated gas turbine models

\begin{tabular}{|l|c|c|}
\hline \multicolumn{1}{|c|}{ GT Model/Design Parameter } & 25MW ICR & 25MW SC \\
\hline TET $[\mathrm{K}]$ & 1500 & 1505.5 \\
\hline Overall Pressure Ratio & 15.52 & 18.75 \\
\hline Intake Mass Flow [kg/s] & 70 & 72 \\
\hline Exhaust Mass Flow [kg/s] & 71.36 & 73.54 \\
\hline Exhaust Gas Temperature $[\mathrm{K}]$ & 660 & 804 \\
\hline Thermal Efficiency $[\%]$ & 42.58 & 37.78 \\
\hline SFC $[\mathrm{g} / \mathrm{KWh}]$ & 196.6 & 221.65 \\
\hline
\end{tabular}

The non-dimensional method of plotting the compressor characteristics implies that all operating conditions covered by values of every pair of $\frac{m \sqrt{T_{1}}}{P_{1}}$ and $\frac{N}{\sqrt{T_{1}}}$ non-dimensional groups yield the relationship between the pressure ratio, temperature ratio and isentropic efficiency. The surge line joins different speed lines where the compressor's operation becomes unstable and the equilibrium running line shows the proximity of the operating zone to the compressor surge line such that when these two intersect each other, the engine will not be capable of being brought up to full power without the need for some remedial action before obtaining a stable operation. Note that a compressor in surge when its main flow passing through it reverses direction for a short interval of time during which the back (exit) pressure drops before the flow resumes its proper direction. The process is followed by a rise in back pressure that causes the low to reverse itself again and if allowed to persist, the unsteady process may result in irreparable damage to the engine. There exists also a condition known as 'choke' which indicates the maximum possible mass flow rate through a compressor at any operating speed.
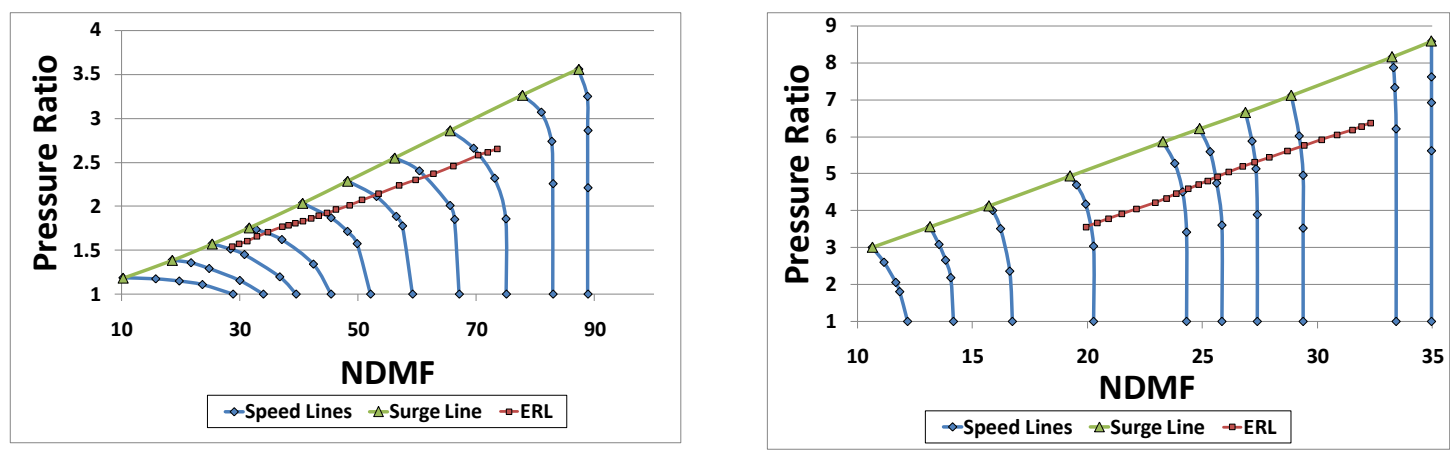

Figure 3: LPC and HPC performance characteristics of the ICR model

An illustration of the LPC and the HPC performance characteristics for the ICR model is shown in Figure 3 while the characteristics of the single HPC of the simple cycle model is as demonstrated in Figure 4.

The effect of varying ambient atmospheric conditions on engine fuel flow for each of the models was investigated to determine the engine performance response to variations in ambient temperature between $(-30)^{\circ} \mathrm{C}$ and $(+45)^{\circ} \mathrm{C}$ for the simple cycle and between $(-25)^{\circ} \mathrm{C}$ and $(+55)^{\circ} \mathrm{C}$ for the ICR. The variation of the turbine entry temperature (TET) at off-design was adopted at intervals of $50^{\circ} \mathrm{C}$ running from $950 \mathrm{~K}$ to a maximum operating temperature of $1550 \mathrm{~K}$ for the simple cycle and between $1000 \mathrm{~K}$ and $1550 \mathrm{~K}$ for the ICR model. This assessment reveals how the fuel flow $(\mathrm{kg} / \mathrm{s})$ of the two models differ with changes in TET such that at lower operating temperatures as low as $1200 \mathrm{~K}$, values of fuel flow for the ICR appear to be less affected by any significant change in ambient conditions. 


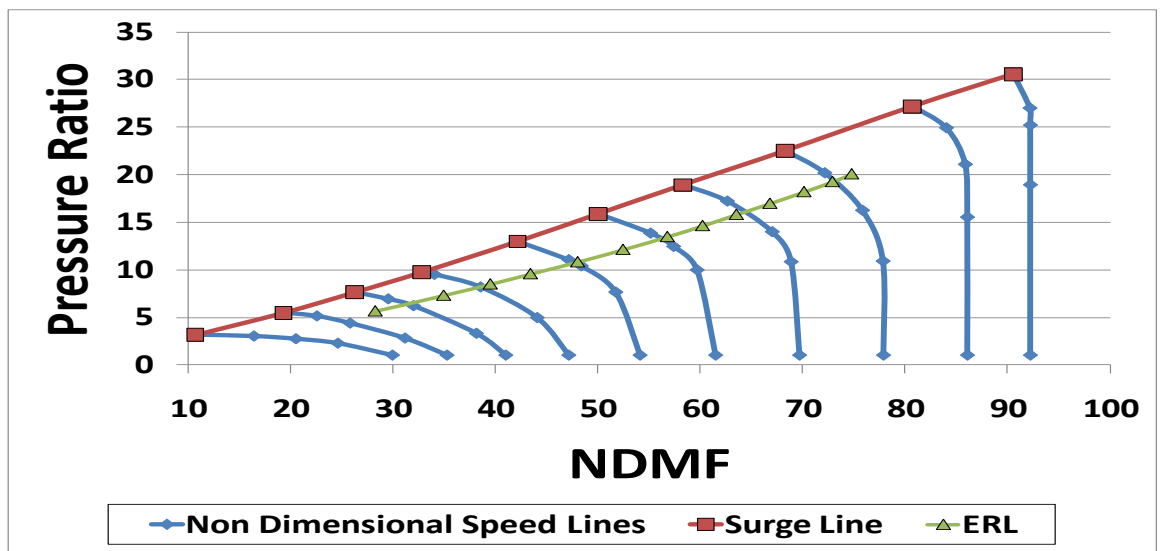

Figure 4: High Pressure Compressor characteristics of the simple cycle model

Under the most adverse investigated scenarios with an ambient temperature of $55^{\circ} \mathrm{C}$, the fuel flow still fell short of $0.6 \mathrm{~kg} / \mathrm{s}$ for the ICR model against a figure of over $1.3 \mathrm{~kg} / \mathrm{s}$ in the case of the simple cycle at a tropical ambient temperature of $45^{\circ} \mathrm{C}$. The advanced cycle shows an off-design maximum value of $1.73 \mathrm{~kg} / \mathrm{s}$ against that of the simple cycle which stands at $2.13 \mathrm{~kg} / \mathrm{s}$ when operating under a high ambient temperature of $55^{\circ} \mathrm{C}$ and $45^{\circ} \mathrm{C}$ respectively.
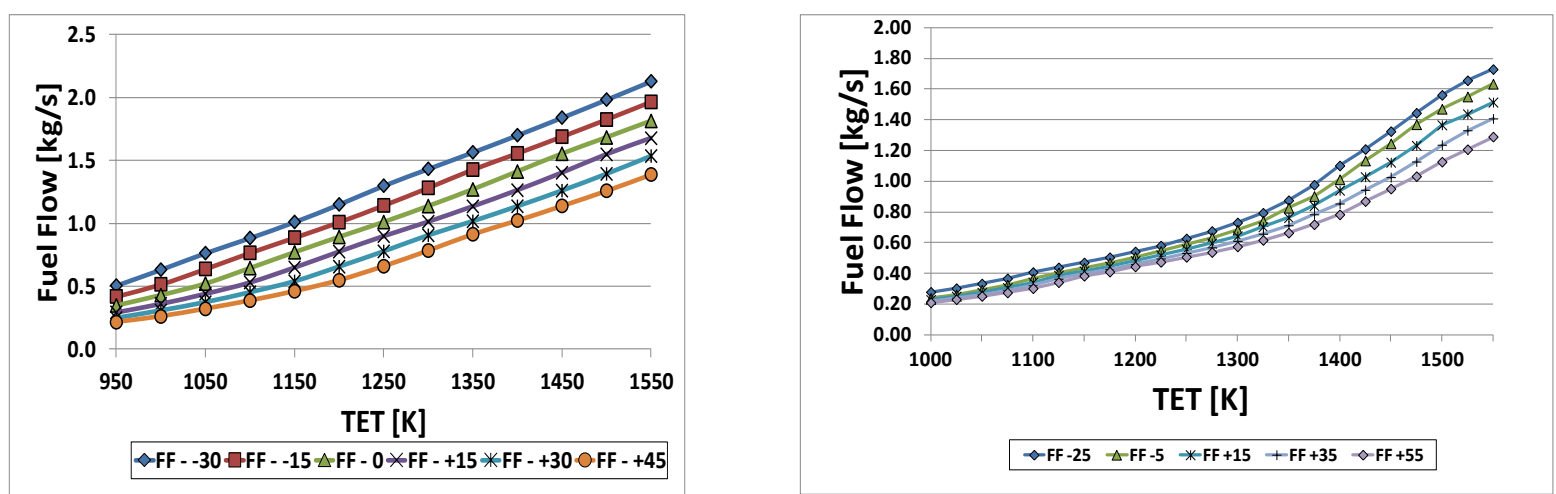

Figure 5: Fuel flow variation for the engine models as affected by changes in ambient conditions

A similar investigation of the thermal efficiency revealed a maximum performance of over $43 \%$ while generating a power output of over $28 \mathrm{MW}$ in contrast to a $37.24 \%$ at a power output of over $27 \mathrm{MW}$.

A reflection of this fuel flow pattern is further illustrated by the SFC and thermal efficiency curves in Figure 6 for comparing the impact of environmental conditions on the marine gas turbine which may depend on season and location of the vessel while navigating in the open sea at any time (season) of the year. It further reveals that the ICR is capable of a SFC of as low as $580 \mathrm{~kg} / \mathrm{s}$ under ambient conditions of $55^{\circ} \mathrm{C}$ while the figure for the simple cycle goes as high as $1400 \mathrm{~kg} / \mathrm{s}$ at an operating temperature of $45^{\circ} \mathrm{C}$ in the open sea. These results further demonstrate the significant part-load performance qualities of the advance cycle gas turbine engine for marine applications.
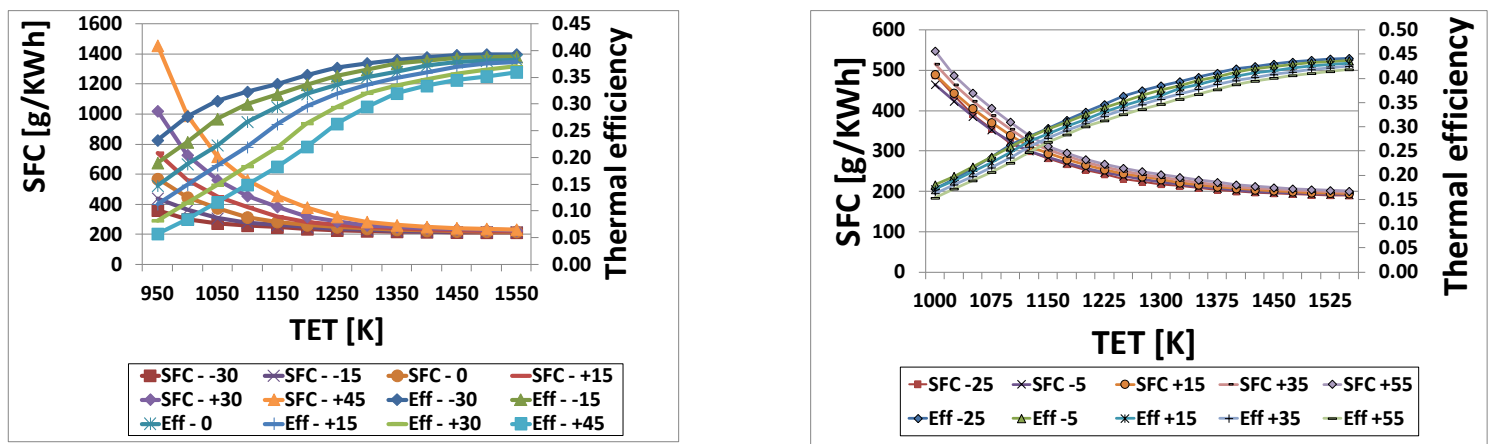

Figure 6: Variation of SFC and thermal efficiency with TET for the simple cycle and the ICR respectively when operated under a variety of ambient temperatures 
A further analysis is illustrated in Figure 7 where the SFC varies with changes in engine power output at the selected ambient temperatures of the study as earlier pointed out in Figure 2 above. It shows that the advanced cycle can be very economical at low power settings of as low as $8 \mathrm{MW}$ combining the gas turbine with either a smaller version or diesel engine for fuel saving purposes.

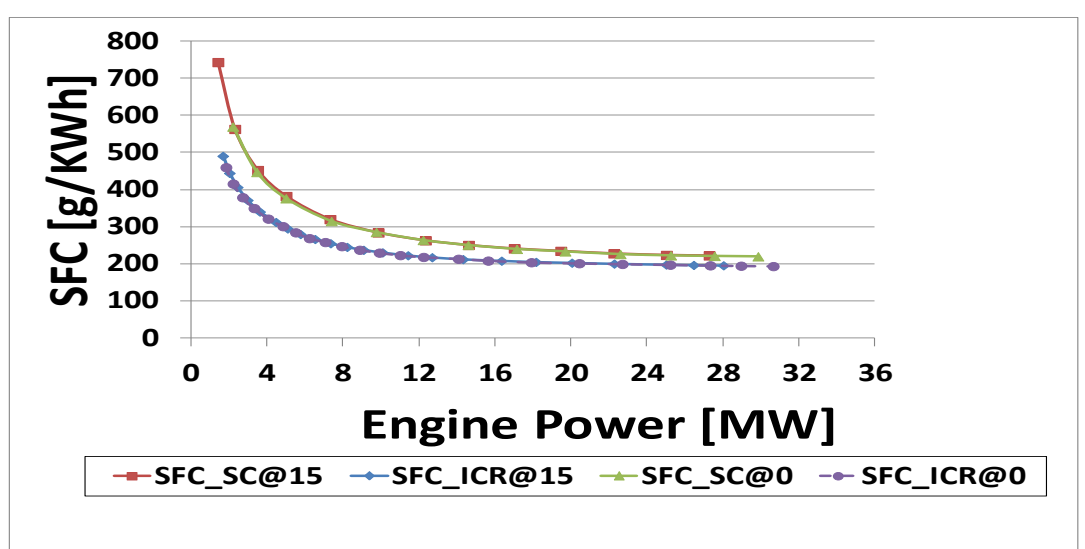

Figure 7: Illustration of the impact of different ambient conditions on the SFC of the models

\section{Conclusions}

This paper assesses the behaviour of the marine gas turbine in response to varying ambient conditions and the potential performance benefits of cold weather operations over that of hot weather. It also explored the advantages of the advanced ICR cycle over the basic simple thermodynamic gas turbine cycle design revealing a higher thermal efficiency of over $43 \%$ contrary to the about $37 \%$ efficiency of the simple cycle option. In spite of its added complexity, it enhances an economic operating cost of any marine vessel installed with marine gas turbines as the propulsion prime mover. The study has also shown how the advanced cycle technology enhances the installation of a more compact propulsion plant that allows for more space to be made available for accommodation of more onboard cargo and avoids the installation of more complex layouts that may necessitate the combination of different types of prime movers such as CODOG or COGOG etc, so as to improve the partload fuel economy particularly during low speed operations. This has been demonstrated by a comparison of the SFC curves for both models, revealing a flat curve for the ICR at significantly lower engine output power of about 8MW for low speed operations much better than the simple cycle option.

\section{References}

[1] Hinks, A. R. (1999), "Aero-Derivative Gas Turbines in the Marine Environment", Gas Turbine Operation and Technology for Land, Sea and Air Propulsion and Power Systems, Vol. 34, 18-21 October, Ottawa, Research and Technology Organization (RTO), France, pp. 11-1.

[2] Woodyard, D. (2004), Pounder's Marine Diesel Engines, Elsevier Butterworth-Heinemann.

[3] Schamp, A., et al (1999), "Experience with Aero-Derivative Gas Turbines as Marine Propulsion Machinery", Gas Turbine Operation and Technology for Land, Sea and air Propulsion and Power Systems, Vol. 34, 18-21 October, Ottawa, RTO, France, pp. 9-1.

[4] GE- Marine, (2006), LM2500 Gas Turbine, General Electric, New York.

[5] GE-Energy (2011), www.ge-energy.com (LM2500 Gas Turbines for Offshore Applications - Fact Sheet) (accessed 05).

[6] Watson, B., (2006), LNG Shipping Operations, Rolls-Royce, UK.

[7] Shepherd, S. B. and Bowen, T. L. and Chiprich, J. M. "Design and Development of the WR-21 Intercooled Recuperated (ICR) Marine Gas Turbine", Journal of Engineering for Gas Turbines and Power, vol. 117, pp. 557-562.

[8] Parker, M. L. et al (1998), "Advances in a Gas Turbine System for Ship Propulsion", RTO AVT Symposium on "Gas Turbine Engine Combustion, Emissions and Alternative Fuels", Vol. MP-14, 12 - 16 October 1998, Lisbon, Portugal, NATO, US, pp. 2-1.

[9] Rowen, A. L. (2003), "Machinery Considerations", in Lamb, T. (ed.) Ship Design and Construction, SNAME, US, pp. 24:1-24:27.

[10] Groghan, D. A. (1992), "Gas turbines", in Harrington, R. L. (ed.) Marine Engineering, The Society of Naval Architects and Marine Engineers, USA, pp. 146-183.

[11] Wiens, B. (1996), "Turbo Expo Shows Off Latest in Gas Turbines", September, pp. 38.

[12] MacMillan, W. L. (1974), Development of a Modular Type Computer Program for the Calculation of GasTurbine Off Design Performance', Doctoral dissertation, School of Mechanical Engineering, Cranfield Institute of Technology, Cranfield, UK

[13] Palmer, J. R, (1967), The 'Turbocode Shceme for the Programming of the Thermodynamic Cycle Calculations on an Electronic Digital Computer, COA/AERO-198, College of Aeronautics, Cranfield Institute of Technology

[14] Palmer, J. R. and Pachidis, V. (2005), The Turbomatch Scheme; for Aero/Industrial Gas Turbine Engine Design Point/Off Design Performance Calculation, Manual, Cranfield University, UK

[15] Sirinoglou, A. (1992), Implementation of Variable Geometry for Gas Turbine Performance Simulation. Turbomatch Improvement, MSc Thesis, SME, Cranfield University, UK

[16] Van den Hout, F. (1991), Gas Turbine Performance Simulation Improvements to the Turbomatch Scheme, MSc Thesis, SME, Cranfield University, UK 